\title{
The role of surface functionalization of silica nanoparticles for bioimaging
}

\author{
Maria C. Gomes ${ }^{*} \uparrow$, Ângela Cunha ${ }^{\star}$, Tito Trindade ${ }^{\dagger}$ \\ and João P. C. Tomé*,\$, \\ ${ }^{*} Q O P N A,{ }^{\dagger}$ CICECO and Department of Chemistry, University of Aveiro \\ 3810-193 Aveiro, Portugal \\ $\$ C E S A M$ and Department of Biology, University of Aveiro \\ 3810-193 Aveiro, Portugal \\ ${ }^{\S}$ Centro de Química Estrutural, Instituto Superior Técnico \\ Universidade de Lisboa, Av. Rovisco Pais, 1049-001 Lisboa, Portugal \\ "Department of Organic and Macromolecular Chemistry \\ Ghent University, B-9000 Gent Belgium \\ "ljtome@ua.pt
}

Received 14 December 2015

Accepted 27 February 2016

Published 20 April 2016

\begin{abstract}
Among the several types of inorganic nanoparticles available, silica nanoparticles (SNP) have earned their relevance in biological applications namely, as bioimaging agents. In fact, fluorescent SNP (FSNP) have been explored in this field as protective nanocarriers, overcoming some limitations presented by conventional organic dyes such as high photobleaching rates. A crucial aspect on the use of fluorescent SNP relates to their surface properties, since it determines the extent of interaction between nanoparticles and biological systems, namely in terms of colloidal stability in water, cellular recognition and internalization, tracking, biodistribution and specificity, among others. Therefore, it is imperative to understand the mechanisms underlying the interaction between biosystems and the SNP surfaces, making surface functionalization a relevant step in order to take full advantage of particle properties. The versatility of the surface chemistry on silica platforms, together with the intrinsic hydrophilicity and biocompatibility, make these systems suitable for bioimaging applications, such as those mentioned in this review.
\end{abstract}

Keywords: Fluorescent silica nanoparticles; bioimaging; surface functionalization; nanoparticlecell interactions.

${ }{ }_{\text {Corresponding author. }}$

This is an Open Access article published by World Scientific Publishing Company. It is distributed under the terms of the Creative Commons Attribution 4.0 (CC-BY) License. Further distribution of this work is permitted, provided the original work is properly cited. 


\section{Introduction}

Silica nanoparticles (SNPs) have a wide range of biomedical applications being already used as drug delivery systems (such as in chemotherapy, photodynamic therapy, gene therapy, protein adsorption, immunoassays) and as bioimaging agents (fluorescent, magnetic resonance imaging (MRI), Raman imaging). ${ }^{1-9}$ Currently, mesoporous and amorphous SNP have been extensively used in the biomedical field. ${ }^{9,10}$ While mesoporous SNP are normally used as drug delivery systems through physical or chemical adsorption, colloidal SNP have been often employed to encapsulate or to graft at the surface

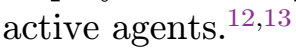

In the past decades, the increasing need to understand the biological processes and environment influences of therapeutic compounds inside biologic systems, led to an increasing search for new bioimaging systems capable of overcoming the limitations of current biomarkers. In fact, the development of biomarkers addresses important aspects concerning biocompatibility, toxicity or aggregation problems that might limit their application in living systems or tissues. In this context, SNP have gained increasing importance as new platforms, i.e., as protecting shells of diverse organic/inorganic compounds and also as coatings of other types of nanoparticles. ${ }^{14-18}$ Important consequences of such type of coating are the improvement of water compatibilty, for molecules poorly soluble, and limitation of eventual detrimental effects occurring in the encapsulated compounds ${ }^{19}$ Besides, SNP are chemically stable at physiological $\mathrm{pH}$ and resist to microbial attacks, making these nanoparticles advantageous over biodegradable ones. ${ }^{20,21}$ Currently, there is a wide range of organic or metal-organic compounds and nanoparticles that have been successfully entrapped in SNP for bioimaging purposes. ${ }^{22-27}$ Also, the easy surface functionalization can decrease biological side effects and increase bioavailability and selectivity. In fact, the interaction between SNP and biological systems can be tailored through smart surface modifications. ${ }^{28}$ Physicochemical interactions of SNP with cell surface, i.e. the electrostatic and dispersion forces between nanoparticles and cell membrane, must be considered. ${ }^{29,30}$ Therefore, it is imperative to understand how biomolecules interact with SNP surfaces and how to manipulate such interaction in order to take full advantage of SNP properties.
Having these challenges in mind, this review will focus on recent efforts for the development of SNP as bioimaging platforms and on the role of surface functionalization on the interactions with biological systems.

\section{SNPs Synthetic Approaches}

Although depending on the chemical properties of the fluorophores, employed as optical active centers, in principle FSNP can be prepared through sol-gel or microemulsion methods. ${ }^{31-33}$ By judicious selection of the experimental parameters, the particle size and shape of the SNP can be tailored. These properties are relevant to control the rate of cellular uptake, biodistribution and targeting efficiency when using such materials as drug delivery vectors. ${ }^{34}$ For example, the stability of SNP in the solvent employed in the synthesis and the rate constants of hydrolysis and condensation of silica oligomers play an important role in determining the final particle size distribution. ${ }^{35-37}$

\subsection{Sol-gel process}

The sol-gel process, aka Stöber method, involves the use of alkoxysilanes as silica precursors that are hydrolyzed to monomeric $\mathrm{Si}(\mathrm{OH})_{4}$ in polar solvents, typically an alcohol (Fig. 1(a)). ${ }^{38}$ The $\mathrm{Si}(\mathrm{OH})_{4}$ molecules condense into silica oligomers via siloxane groups that end up in amorphous silica network. Both hydrolysis and condensation steps occur simultaneously and the use of an acidic or basic catalyst allows the entire process to be kinetically faster. For example, the hydrolysis of tetraethylorthosilane (TEOS) in ethanol is catalyzed by ammonia giving rise to monodispersed solid SNP ranging in size from nano- to micro-sized silica particles $(50 \mathrm{~nm}$ to $2 \mu \mathrm{m}) .{ }^{31}$ Despite the stability of these particles in solution, the monodispersity degree of the colloids can vary depending on the electrostatic repulsion between the negatively charged SNP. ${ }^{39}$ This aspect has been widely used in the fields of materials science and ceramic engineering for the production of silica based materials. ${ }^{40}$ Recently, Hartlen and Yokoi used a new approach to obtain monodispersed SNP with $12 \mathrm{~nm}$ of average diameter. ${ }^{41-43}$ In this case, they replace the basic catalyst ammonia by lysine or arginine, maintaining the aqueous medium. This new system, 


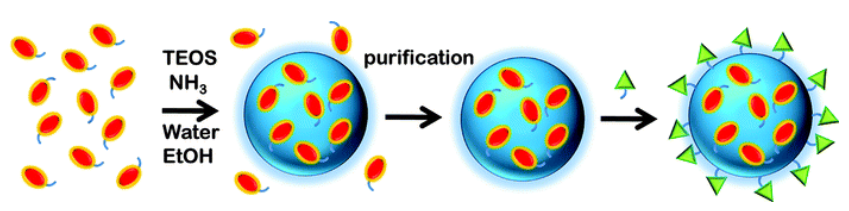

(a)

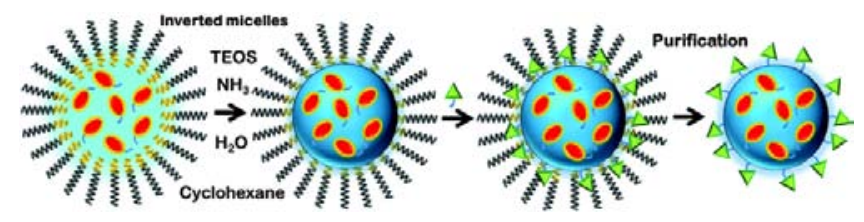

(b)

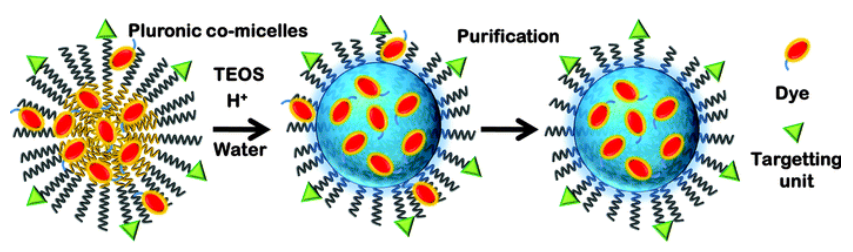

(c)

Fig. 1. Scheme of methods employed for the synthesis of SNP. (a) The sol-gel method in which the hydrolysis and condensation reactions using alkaline catalysis. (b) The reverse phase microemulsion $(\mathrm{W} / \mathrm{O})$ in which TEOS is hydrolyzed at the micellar interface and enters the aqueous droplet to form a SNP within the micelle. (c) The direct phase microemulsion $(\mathrm{O} / \mathrm{W})$ in which organotrialkoxysilane precursors are hydrolyzed within the nonpolar core of surfactant microemulsion. Reproduced from Ref. 1 with permission of The Royal Society of Chemistry.

unlike the common Stöber method, show a slow hydrolysis of TEOS. The authors attributed this phenomenon to the emulsion system, where the hydrolysis of TEOS occurred at the interface between water (amino acid and water) and the oil phases (TEOS).

\section{2. $\quad W / O$ microemulsion}

Another common method uses the reverse phase or $\mathrm{W} / \mathrm{O}$ microemulsions (Fig. 1(b)). ${ }^{44}$ This system involves nanometer-sized water droplets stabilized by a surfactant in a predominantly organic phase. Here, the hydrolysis and condensation occurs in the interface of the micelles which act as "nanoreactors" assisting the control of particle formation due to hydrolysis and condensation of silica oligomers. ${ }^{32}$ This method allows the controlled hydrolysis of the alkoxysilane (e.g., TEOS), giving rise to fairly uniform and monodispersed colloidal SNP samples for which the average size is usually smaller than $100 \mathrm{~nm} .{ }^{44}$ Ternary (surfactant/oil/water) or quaternary (surfactant/co-surfactant/oil/water) W/O microemulsions have been used as reacting medium in this synthetic method. ${ }^{45}$ Santra and co-workers obtained $50 \mathrm{~nm}$ sized RuBpy-loaded SNP using a quaternary $\mathrm{W} / \mathrm{O}$ microemulsion. ${ }^{46} \mathrm{~A}$ few years later, Bagwe and co-workers succeeded in synthesizing RuBpy-loaded SNP, obtaining nanoparticles with $30 \mathrm{~nm}$ of diameter, through a ternary $\mathrm{W} / \mathrm{O}$ microemulsion. ${ }^{47}$ Usually this specific system is used when organic or inorganic particles, such as dyes, quantum dots (QDs) or magnetic nanoparticles require coating for bioapplications. ${ }^{44}$

\section{3. $O / W$ microemulsion}

More recently, a new approach based on organic modified silica (ORMOSIL) nanoparticles (Fig. 1(c)) has been reported as new platforms for biochemical derivatization. ${ }^{48}$ These systems, typically within 20-30 nm diameter range, are obtained through an $\mathrm{O} / \mathrm{W}$ microemulsion made up of dimethylsulfoxide (DMSO), water, 1-butanol and surfactant. In this case, lipophilic organosilane derivatives, such as octyltriethoxysilane (OTES) or vinyltriethoxysilane (VTES) have been used directly in the micelle solution. ${ }^{1}$ In general, SNP are synthesized by alkaline hydrolysis and polycondensation of organotrialkoxysilane precursors within the nonpolar core of Tween-80/water microemulsion. ${ }^{49}$ The presence of the surfactant and the low reticulation derived from the trialkoxysilane precursors leads to some mesoporosity and risk of leaching of the loaded compounds. Therefore, this methodology requires the covalent linkage of the loaded compound.

\section{Fluorescent Silica Nanoparticles}

Fluorescent-based bioimaging has developed considerably in the last decades, and high-resolution and super-resolution technologies are currently applied in biological and biomedical protocols. Although a large variety of organic dyes, fluorescent proteins and luminescent metal-complexes have been used, its high photobleaching-rates (limiting its use in long-terms tracking), short fluorescent lifetimes, toxicity and aggregation are still relevant limitations. ${ }^{50}$ In this context, SNP revealed to be an important auxiliary platform. In fact, dye loaded 
SNP allow regions to be easily visualized by fluorescence because an high amount of fluorophore is accumulated in each single particle. ${ }^{51}$ SNP are optically transparent at the wavelength region for fluorophore excitation thus allowing to keep fluorescence excitation and emission characteristics of the incorporated dyes. ${ }^{45,52,53}$ Additional features such as robustness, mechanical stability, and low-toxicity make SNP suitable fluorophore nanocarriers. ${ }^{54-56}$

The synthesis of fluorescent silica nanoparticles (FSNP) relies on the strategies previously described. Depending on the chemical properties of the fluorophore, it is possible to prepare SNP through the sol-gel or microemulsion methods. ${ }^{31-33,52}$ In fact, it is possible to entrap more than one type of fluorophores, hence taking advantage of different fluorescence emission spectra. $\mathrm{Xu}$ et al. successfully entrapped fluorescein-5-isothiocyanate (FITC) and $\mathrm{Ru}(\text { phen })_{3}^{2+}$ in SNP and optimized fluorescence properties by varying the ratio between the two fluorophores (Fig. 2). ${ }^{57}$ Maintaining the concentration of FITC, they observed that the wavelength region of the emission band shifted from green (FITC alone) to light orange (equal amount of both) and finally to red (10 times higher amount

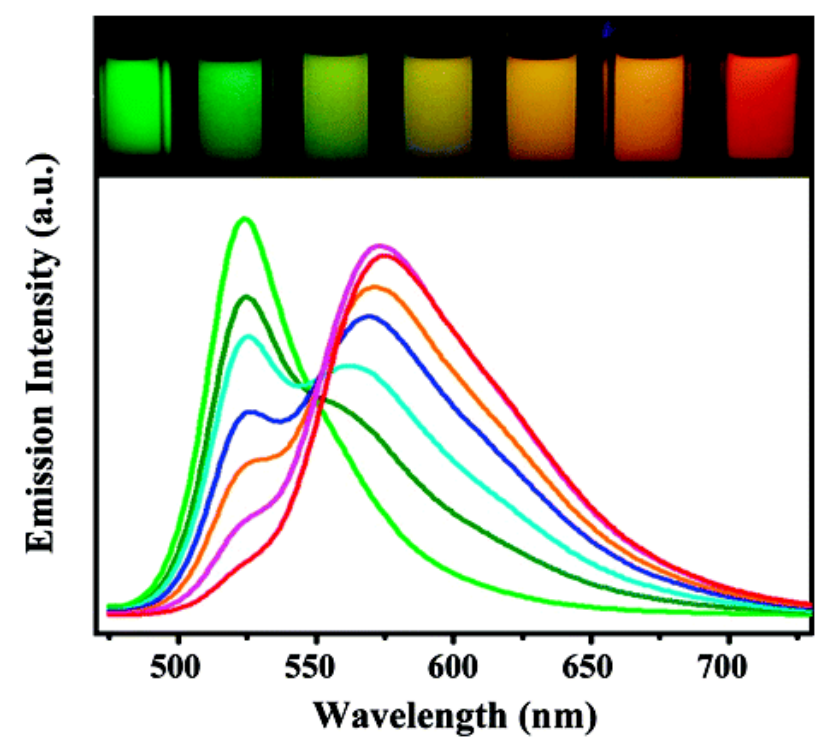

Fig. 2. (Top) Dispersions of FSNP under a $365 \mathrm{~nm}$ UV lamp. The amount of FITC was $0.06 \mathrm{mg}$, while those of $\mathrm{Ru}(\mathrm{phen}){ }_{3}^{2+}$ were $0 \mathrm{mg}, 0.0 \mathrm{mg}, 0.02 \mathrm{mg}, 0.04 \mathrm{mg}, 0.06 \mathrm{mg}, 0.10 \mathrm{mg}$, and $0.15 \mathrm{mg}$, respectively (from left to right). (Bottom) emission spectra of the stepwise SNP. Reprinted with permission from Ref. 55 Copyright (C) 2010 American Chemical Society. of $\left.\mathrm{Ru}(\mathrm{phen})_{3}^{2+}\right)$, with the increase of $\mathrm{Ru}(\mathrm{phen})_{3}^{2+}$ amount.

The covalent attachment of Alexa Fluor in 20-100 nm SNP originated fluorescent nanoparticles with the same excitation and emission features as the free label. ${ }^{58}$ On the other hand, AlRawi et al. performed a different study using FITC as fluorophore and unlabeled (plain), nonporous and amorphous $70 \mathrm{~nm}, 200 \mathrm{~nm}$, and $500 \mathrm{~nm}$ SNP (Fig. 3 (a)). ${ }^{59}$ Taking advantages of the fluorescence properties of these FSNP, they were able to assess the intracellular size-dependence distribution of FSNP in HeLa cells through high-resolution confocal laser scanning microscopy (HRCLSM) (Fig. 3(b)). They observe that all sizes of FITC-SNP tested were taken up into the cytosol of HeLa cells being located near the nucleus.

As mentioned before, amorphous silicas have also been used as protecting shells for other nanoparticles, such as quatum dots (QDs). Ma et al. were able to entrap QD into SNP, through a sol-gel process. ${ }^{60}$ The SNP obtained were $30 \mathrm{~nm}$ core-shell nanoparticles, highly luminescent, photo and colloidal stable with features suitable for cellular biomarking. Cao et al. have reported the noncovalent incorporation of hydrophobic $\mathrm{ZnS}: \mathrm{Mn}^{2+}(3 \%)$ QD in SNP through the reverse microemulsion method. ${ }^{61}$ TEM analysis revealed that each SNP contained a single QD as the core and the red fluorescence allowed the assessment of the intracellular localization in HeLa cells. Lanthanides (Ln III) based compounds have also been entrapped in SNP shells giving rise to materials that exhibit photoluminescence behavior typical of $\operatorname{Ln}(\mathrm{III})$ as emitting centers. ${ }^{62-69}$ Among the properties that make these compounds very interesting for bioimaging are the large Stokes shifts and sharp emission profiles with fluorescence lifetimes in the order of milliseconds, unlike commonly used organic dyes. ${ }^{70-76}$ In fact, longer lifetimes represent a significant advantage, allowing a simple and accurate discrimination of the Ln(III) signal from auto fluorescence (background biological fluorescence) through time-resolved measurments. ${ }^{70,73,77}$ Granadeiro et al. studied the fluorescence behavior of several lanthanopolyoxotungstates ( $\mathrm{Ln}(\mathrm{III})-\mathrm{POM})$ ) entrapped in SNP. ${ }^{78}$ They successfully obtained a core-shell nanostructure with the $\mathrm{Ln}$ (III)-POM mainly located in the nanoparticle core. According to their results, the photophysical characteristics of the Ln(III) compounds could be adjusted by using an aromatic 


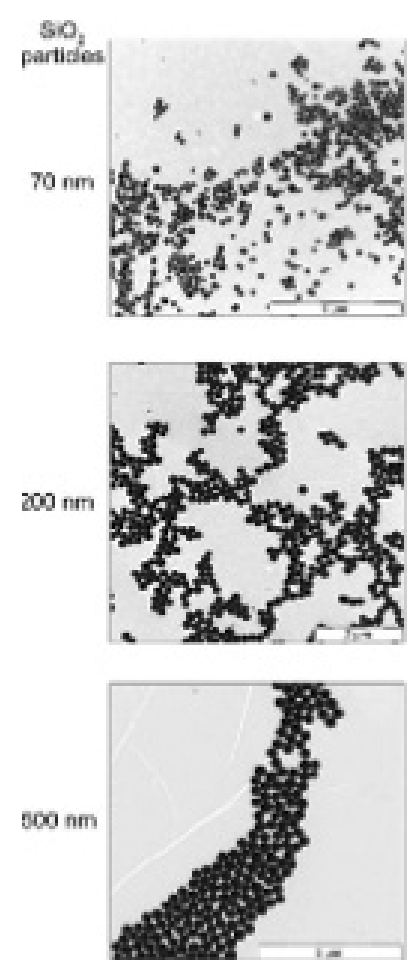

(a)

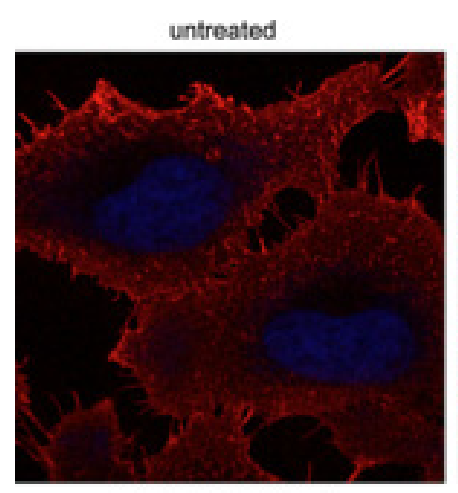

$200 \mathrm{~nm}$ SiO,-SMPs

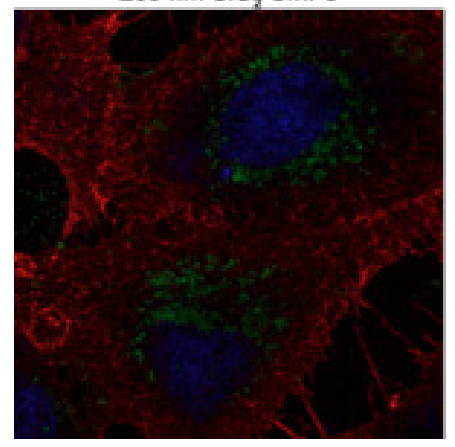

(b)

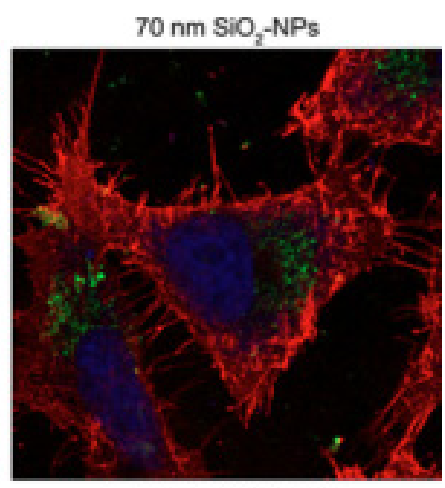

$500 \mathrm{~nm} \mathrm{SiO},-S M P s$

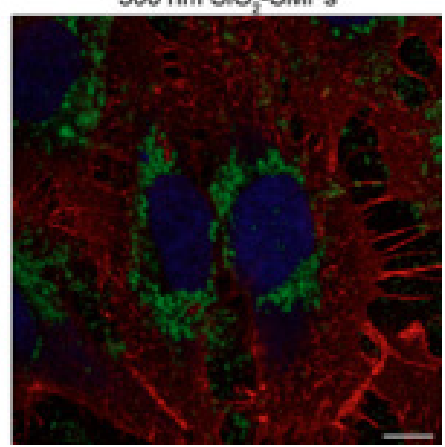

Fig. 3. (a) Size and morphology of the FITC-SNP. (b) Localization of the FITC-SNP (green) in HeLa cells assessed by HRCLSM. HeLa cells were exposed to $70 \mathrm{~nm}, 200 \mathrm{~nm}$ and $500 \mathrm{~nm}$ SNP or left untreated for $24 \mathrm{~h}$. Blue refers to nuclear marker, red to membrane marker and green to FITC-SNP. Reprinted with permission from Ref. 57. Copyright (c) 2011 Springer-Verlag.

organic ligand as an antenna for energy transfer. Zhang et al. also prepared a visible-light-excitation wavelength europium SNP (EuSNP) biolabel with stronger and longer luminescence lifetime and, evaluated its sensitivity in imaging of living cell through the use of time-resolved mothods. ${ }^{79}$ $\mathrm{Wu}$ et al. have reported extensive studies using $\mathrm{Eu}(\mathrm{III})$-emissive mesoporous SNP (EuMSNP) for highly-luminescent in vitro cell and in vivo lymphatic bioimaging, obtaining excellent photostable low-toxicity nanoparticles without dissociation in PBS buffer. ${ }^{80}$

Besides cell labeling, FSNP also proved to be suitable as fluorescent nanoprobes for chemosensors of $\mathrm{pH}$, oxygen, ionic species, and for protein and DNA detection and separation. ${ }^{52,81,82}$ Modified $150 \mathrm{~nm}$ mesoporous SNP, covalently loaded with a specific luminogen, were prepared by Miao et al. as a fluorescent sensor for detecting explosives in water. ${ }^{83}$ These FSNP showed good dispersion in water with fast fluorescence quenching response. Liu et al. also take advantage of the FSNP and prepared a $\mathrm{pH}$ sensor with acridine orange as organic dye. ${ }^{84}$ In this case, core-shell nanoparticles (average diameter $170 \mathrm{~nm}$ ) with excellent selectivity, stability and high reproducibility have been obtained through simple reverse microemulsion. Tan et al. attempted another application for $\operatorname{Ln}(\mathrm{III})$-based FSNP. They developed a dual-emission fluorescent probe for mercury detection in water and milk, through the combination of two $\operatorname{Ln}(\mathrm{III})$ chelates with different emission wavelengths. ${ }^{85}$

\section{SNPs Surface Functionalization}

The surface's properties of SNP play a key role in the extent of the interaction between nanoparticles and biological systems. ${ }^{86-88}$ Hence, surface modification methods have been used aiming to improve the colloidal stability of SNP in biological systems and increase circulation times, as well as to reduce overall toxicity and aggregation. ${ }^{89}$ Bare colloidal SNP have the surfaces negatively charged at physiological $\mathrm{pH}$ due to the ionization of the hydroxyl groups $(-\mathrm{OH})$. In certain conditions, such SNP can 
be colloidal stable for prolonged times, either in serum-free medium or in complete medium containing $10 \%$ serum. However, it is important to note that, due to the negative surface charge, bare SNP are promptly enclosed within a corona of proteins and therefore it is actually the hybrid nanostructure composed of silica core/protein nanostructure that interacts with cell surfaces. ${ }^{29,30}$ The SNP negative surface charge can be used with advantage for subsequent surface modifications either via covalent coupling using silane chemistry or, via physical adsorption or electrostatic interactions (Fig. 4).,11 SNP surface can be functionalized by distinct types of systems of relevance for biointeractions, such as antibodies, folic acid, aptamers, PEG, carbohydrates, lipids, amongst others. ${ }^{15,90-92}$

Covalent functionalization at the silica surfaces is possible by the well-established silane chemistry, mediating strong linkages between the SNP surface and selected biomolecules. ${ }^{93,94}$ A large library of commercially available halosilanes and alkoxysilanes is currently available, allowing the introduction of functional groups like amines, carboxylates, epoxides and thiols. Despite being wellestablished, silane chemistry can present some drawbacks, that result in steric hindrance, variation in reactivity, depending on the coupling agents used, and limitation to molecules with reactive groups for the covalent linking step. ${ }^{95}$ However, the conjugates formed through this type of chemistry are less influenced by external conditions such as protein concentration, $\mathrm{pH}$ and ionic strength.

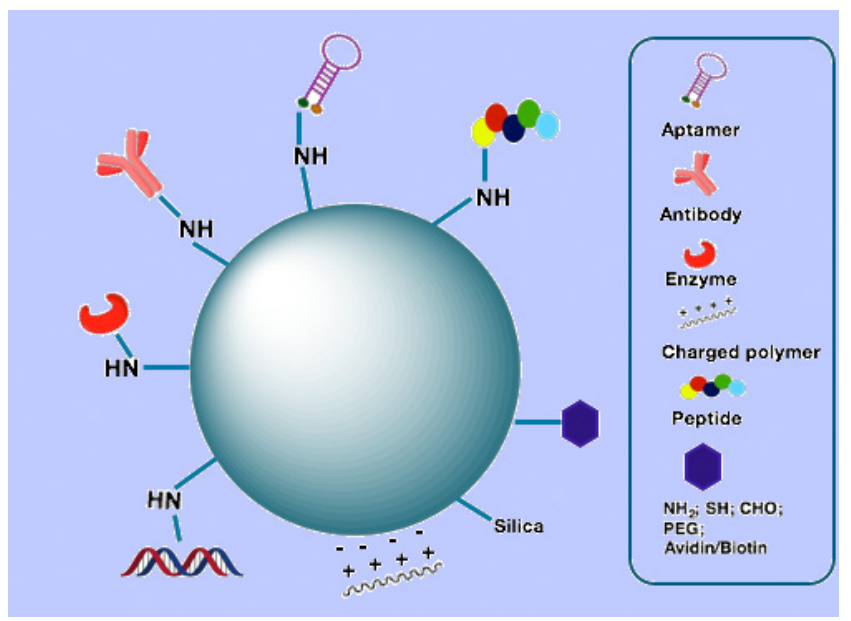

Fig. 4. Schematic illustration of the surface functionalization of SNP with, peptides, antibodies, aptamers, enzymes, DNA fragments and other functional groups.
For these purposes, 3-aminopropylrietoxysilane (APS) has been a commonly used coupling agent because besides promoting strong covalent linkages onto the SNP surfaces, the protonated amine groups, at physiological $\mathrm{pH}$, also allow electrostatic interaction with negatively charged species, such as DNA or proteins. Zhao et al. have reported the use of coated fluorescent SNP as probes for the galactose/3-sulfogalactose carbohydrate-carbohydrate interaction. In this case, SNP were first functionalized with the azidosiloxane and then, galactose moieties were stapled through copper-promoted click reactions. ${ }^{96}$ Surface functionalization with polyethylene glycol (PEG) has been extensively used and is another example of such type of surface modification. ${ }^{11,97-99} \mathrm{PEG}$ is a polymer that in these situations act as a protective layer around SNP surface, hiding the silanol groups from the bulk liquid medium and stabilizing the colloidal particles at high salt conditions, whereas in similar conditions bare SNP would aggregate irreversibly. ${ }^{34}$ Xie et al. functionalized MSNP with carboxyl groups and then conjugated folate via PEG 2000, used as a hydrophilic spacer. While the introduction of PEG increased the water dispersibility of MSNP, the folate modification enhanced the cellular uptake in KB cells, when compared to the unmodified MSNP counterparts. ${ }^{100}$

SNP surface can also be modified through adsorption or electrostatic interactions with large molecules. Very often, this method has been used to attach biomolecules such as lipids, proteins, antibodies or polymers that, due to its opposite charges, interact with the surface of colloidal nanoparticles. ${ }^{32,101,102}$ In this case, nanoparticles curvature as well as protein molecular weight, affect surface functionalization. ${ }^{103}$ Noncovalent attachment is a simple and not expensive method, enabling surface exchange reactions that result in the replacement of previously attached molecules by others that have higher affinity to the SNP surface but having no specificity to the cells in study. Moreover, conformational changes and protein denaturation or changes in $\mathrm{pH}$ can lead to faster rates of desorption from the nanoparticle surface. ${ }^{32}$ Yang et al. worked with a mixture of lipids (DMPA/DMPC, 10:90) and demonstrated that for this system the adsorption depended little on electrostatic attractions. ${ }^{104}$ Another application of this type of electrostatic interactions is the layer-by-layer (LbL) method, where alternating layers of cationic and anionic polyelectrolytes are 


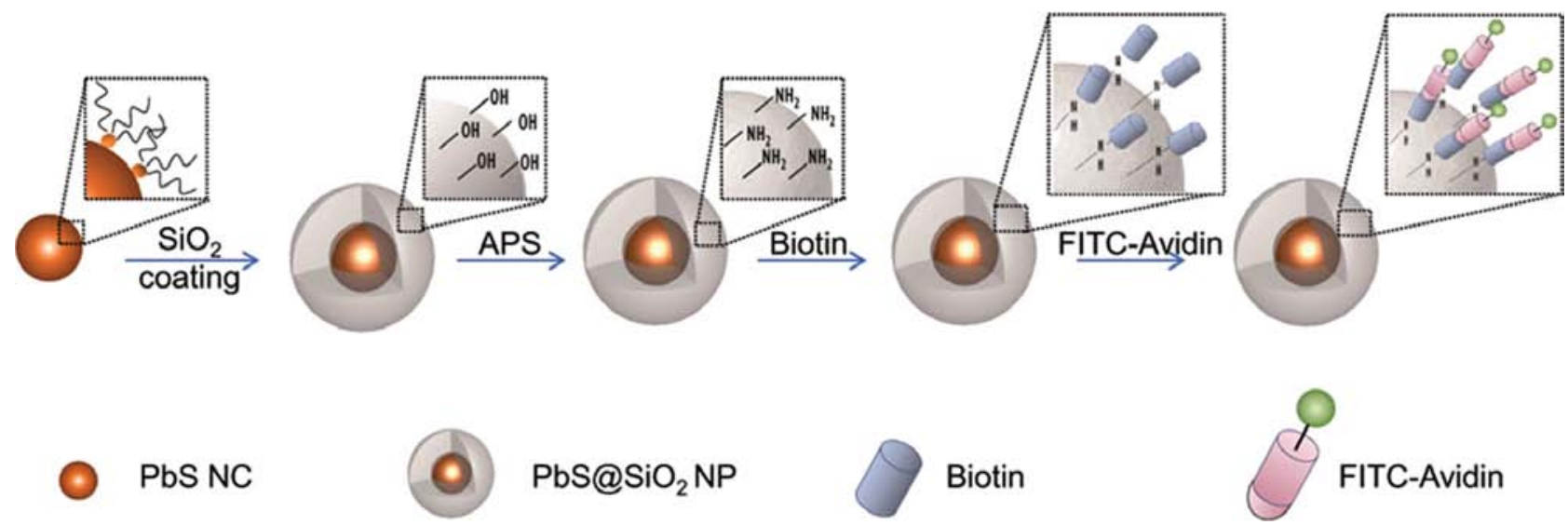

Fig. 5. General scheme for the PbS NC functionalization process leading to the conjugation of PbS@SNP with biotin and subsequent conjugation with streptavidin. Successive steps in sequence (from left to right): silica coating of organic capped PbS NCs; PbS@SNP surface modification with amine groups; bioconjugation reaction with biotin; molecular recognition with FITCmodified streptavidin. Reprinted with permission from Ref. 101 Copyright (c) 2014 Royal Society of Chemistry.

coupled to SNP surface to mediate the interaction with charged biomolecules. ${ }^{103,105,106}$

Another type of SNP surface functionalization takes advantage of the strong binding affinity between streptavidin and biotin, which has been a type of conjugate intensively used in several bioanalytical protocols. ${ }^{107}$ Corricelli et al. have explored this type of noncovalent binding to produce colloidal stable core-shell $\mathrm{PbS} / \mathrm{SiO} 2 \mathrm{NP}$ in physiological media (Fig. 5). ${ }^{108}$ Firstly, biotin was covalently attached via amine groups present in SNP surface, after which a FITC-Avidin complex was added. Streptavidin is often used in biomolecular functionalization because of its resistance to $\mathrm{pH}$, moderate temperature variations, proteolytic enzymes and denaturants. ${ }^{32}$

\section{Effects of Surface Functionalization on Nanosilica-Cell Interactions}

Several studies have demonstrated that SNP size and shape affect nanoparticle internalization by cells. However, the type of interaction with biological systems will also be dictated in large extent by the surface properties of SNP (chemical functionality, surface charge, and composition with biomolecular functionalization), namely because internalization depends on cell membrane recognition. ${ }^{109-112}$ Thus not only the colloidal and chemical stability of the biomolecule/nanoparticle complex should be considered but also physicochemical interactions between SNP and the cell surface should be addressed. ${ }^{29,30}$ There is an increasing awareness that in studying nanoparticle-mediumcell systems a single bioinorganic entity should be considered for most practical situations. ${ }^{113}$ Several studies have demonstrated that SNP surface design (ligand nature) affects the interaction with serum proteins and cell membrane receptors, and consequently, the pathway by which cells internalize nanoparticles, and ultimately determine intracellular localization. . $^{110,114}$

The cellular incorporation of external entities may occur through different pathways (direct diffusion or disruption, endocytosis, ion channels or through transmembrane pump). ${ }^{109,115}$ In the specific case of SNP, endocytosis (a mechanism that requires energy input by the cell) is the major pathway of translocation to the intracellular compartment. ${ }^{109}$ However, depending on the degree of surface functionalization, SNP may be internalized through fluid phase (Fig. 6(a)) or receptor-mediated endocytosis (Fig. 6(b)). ${ }^{116}$ The presence of suitable functional groups on SNP surface may enhance the binding to specific target receptors present in the cellular membrane. Sandoval et al. designed folate and PEG functionalized SNP with the fluorescent reporter fluorescein isothiocyanate. ${ }^{117}$ Using confocal microscopy it was possible to estimate that $27 \%$ of PEG-functionalized nanoparticles adhering to cell surface were endocytosed against a $95 \%$ endocytosis for the folate-functionalized nanoparticles. The presence of over-expressed folate receptors in many human cancer cells confers the basis for the enhanced specificity of folate-functionalized nanoparticles. After binding, a closed vesicle 


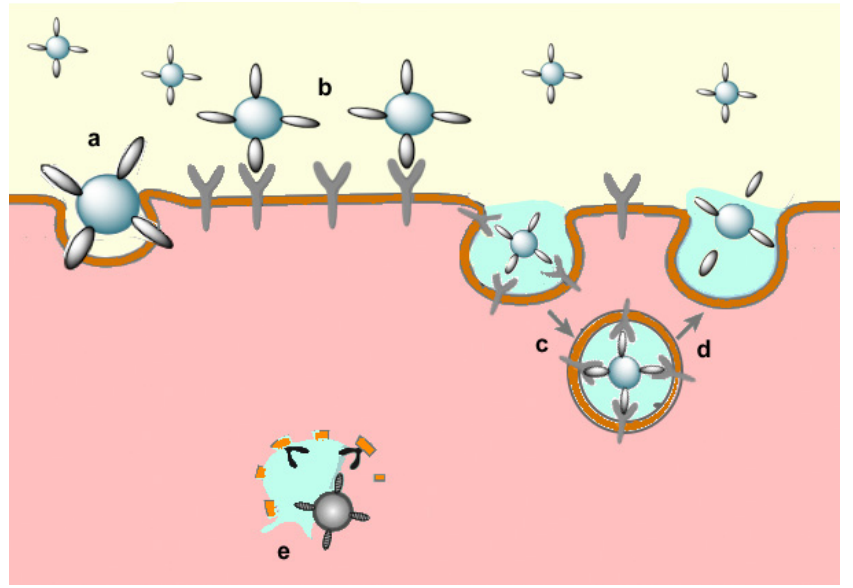

Fig. 6. Surface functionalized nanoparticles interacting with cells. (a) Nanoparticles bind to receptors on the membrane and induce a signaling cascade without entering the cell. (b) Nanoparticles can also be internalized and exocytosed by the cell, without ever leaving the vesicle. (c) Internalized nanoparticles can escape the vesicle and interact with various organelles. (d) Nanoparticles can interact nonspecifically with the cell surface membrane, and be internalized.

structure may be formed allowing the nanoparticles entering into the cell via receptor-mediated endocytosis, forming endosomes (Fig. 6(c)). ${ }^{118}$ However, the levels of expression of cell membrane receptors, as well as surface ligand coverage extension may also dictate the success of internalization. ${ }^{116}$ Pritz et al. characterized the endocytic trafficking of bare SNP within HEI-OC1 cells. ${ }^{119}$ SNP were internalized into early endosomes after 20 min and reached the lysosomes after $2 \mathrm{~h}$ of incubation. However, endosomal escape was not observed. This inability to be released from endosomal vesicles prevents their use as cytoplasmatic or nuclear imaging agents. ${ }^{32}$ In the majority of the cases, nanoparticles can be exocytosed by the cell without leaving the vesicle (Fig. 6(d)). In some cases, SNP may escape from endosomes (Fig. 6(e)) and target specific sub-cellular structures, which requires that the endosome membrane must disrupt. ${ }^{116}$ For this to happen, the endosome membrane must be disrupted. SNP surface functionalization nature may play an important role in the process of membrane disruption. ${ }^{120}$ Several studies have shown that cationic SNP bind to cells more efficiently than neutral or anionic ones, because the electrostatic affinity to the negatively charged cell membrane increases endocytosis efficiency. ${ }^{110,121,122}$ However, as shown by Slowing et al. anionic SNP present higher ability to escape endosomes because of the proton sponge effect, i.e., to the better buffering capacity, which is important for endosome escape. ${ }^{123}$

Besides endocytosis, the surface functionalization of SNP affects the exocytosis profile. Yanes et $a l$. have conducted three different types of surface modifications (using phosphonate, folate, or polyethylenimine (PEI)) in mesoporous SNP. ${ }^{124}$ The rate of nanoparticle release was directly related with surface nature. After $6 \mathrm{~h}, 84 \%, 66 \%$, and $49 \%$ of the phosphonate, folate and PEI-functionalized mesoporous SNP were released, respectively. The results demonstrated that in addition to the protective character, the presence of PEI on SNP extended nanoparticle lifetime in biological environments.

One of the advantages of using FSNP is the possibility of using fluorescent techniques to study nanoparticle cell interactions (e.g., mechanisms of cellular uptake, changes in cell morphology, SNP surface effects). Shahabi et al. have addressed the effect of surface charge on FSNP cellular uptake. Through $\mathrm{W} / \mathrm{O}$ reverse microemulsion, rhodamine B isothiocyanate was incorporated in the SNP matrix, introducing thereafter ratios of amino and sulfonate groups onto nanoparticles surface (diameter $\approx 58 \mathrm{~nm}$ ) and tested the SNP uptake and intracellular localization in the presence or absence of serum (FCS). ${ }^{125}$ While in absence of serum (Fig. 7(a)) positively charged SNP were better internalized by human osteoblasts (HOB), for the serum-containing medium (Fig. $7(\mathrm{~b})$ ) the negatively charged ones were preferred.

$\mathrm{Tu}$ et al. also studied the effect of different surface-functionalized mesoporous SNP taking advantage of fluorescence properties. ${ }^{126}$ Mesoporous SNP were loaded with phthalocyanines $(\mathrm{ZnPc})$ through the $\mathrm{O} / \mathrm{W}$ microemulsion method and the surface was functionalized with PEI and PEG-PEI ligands. Due to the fluorescence exhibited by the $\mathrm{ZnPc}$ it was possible to use confocal microscopy to assess the lysosome disruption capability of both PEI- and PEG-PEI-functionalized SNP and to compare the results with those in which bare SNP were used instead. Results suggested that PEI- (73\%) and PEG-PEI-functionalized (53\%) SNP displayed higher efficiency in the escape from the endosomes to the cytosol than bare nanoparticles that was attributed to the proton sponge effect caused by PEI. This study also revealed that PEI- and PEGPEI-functionalized SNP have higher selectivity to tumor cells than bare SNP. 

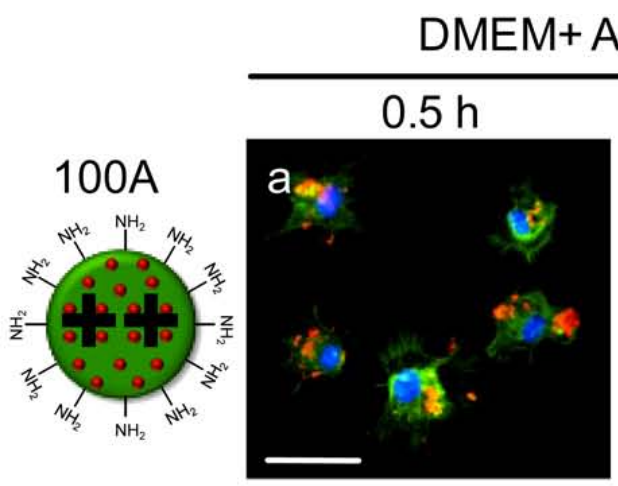

$\frac{\operatorname{AB} / \mathrm{AM}(1 \%)}{6 \mathrm{~h}}$
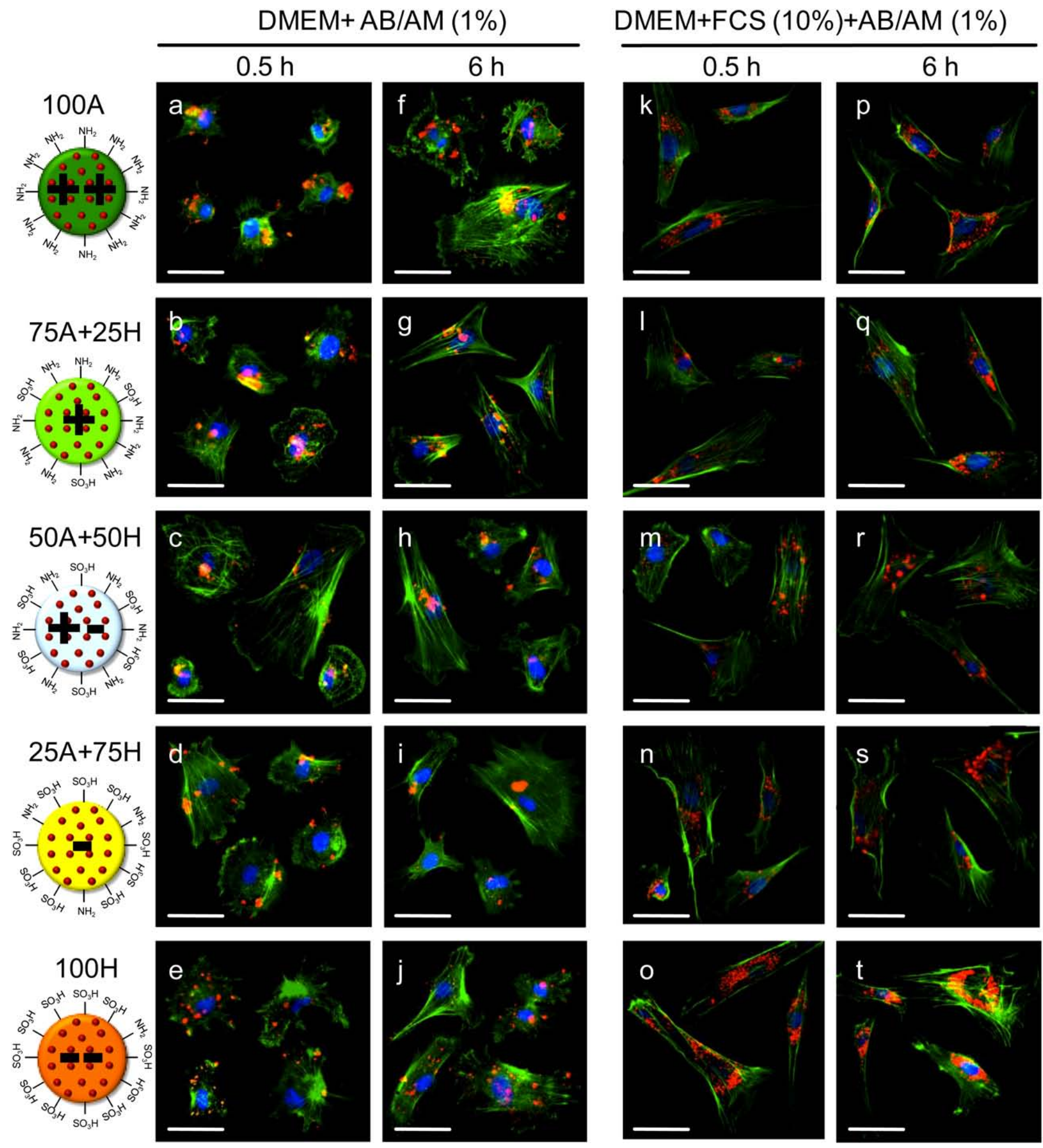

Fig. 7. Fluorescence microscopy micrographs of HOB osteoblasts incubated without $(\mathrm{a}-\mathrm{j})$ or with $(\mathrm{k}-\mathrm{t}) \mathrm{FCS}$ for 0.5 or $6 \mathrm{~h}$ at $37^{\circ} \mathrm{C}$ with $100 \mu \mathrm{g} \mathrm{mL}^{-1} \mathrm{FSNP}$, revealing cellular uptake and intracellular localization of the particles. Green, blue, and red fluorescence indicates the actin cytoskeleton, the nuclei, and FSNP, respectively. Scale bars: $50 \mu \mathrm{m}$. Reprinted with permission from Ref. 115 . This is an unofficial adaptation of an article that appeared in an ACS publication. ACS has not endorsed the content of this adaptation or the context of its use. Copyright (c) 2015 American Chemical Society. 


\section{Impact on Biodistribution, Biocompatibility and Cytotoxicity}

In the last decades, a huge effort has devoted to the evaluation of parameters that can affect SNP biocompatibility. ${ }^{118,127-129}$ However, there is still considerable uncertainty on this topic, namely because reported results are widely variable and often contradictory. Despite the controversy, there is a general consensus on the relation between SNP physicochemical properties and its biocompatibility. Although experimental results have provided evidence that particles' properties such as size, shape and surface chemistry are related to important biological SNP effects, still controversy raises from the fact that the effects of different parameters are interdependent and cannot be interpreted separately. ${ }^{116,130,131}$ In this matter, FSNP can represent some advantage over fluorophore-free nanoparticles since the effect of SNP on cells can be directly observed. For example, Soenen et al. have used commercially available bare-FSNP (C-Spec ${ }^{\circledR}$ particles) and several cell-nanoparticle size $(25 \mathrm{~nm}, 45 \mathrm{~nm}$ and $75 \mathrm{~nm})$ interaction studies were conducted, addressing namely the effect on cell morphology (Fig. 8). ${ }^{132}$ For noncytotoxic SNP concentrations, none of the tested SNP caused significant alterations in cell morphology.

Silanol groups ( $\mathrm{Si}-\mathrm{OH})$ have an active role in the ROS generation inside cells, which ultimately can lead to cell death. ${ }^{133}$ However, as mentioned above, the surface silanol groups can be easily functionalized decreasing SNP toxicity and thereby promoting biocompatibility like the SNP prepared by $\mathrm{He}$ et al. where the reduced toxicity was interpreted on the basis of the PEG surface functionalization employed. ${ }^{134}$ Several authors have demonstrated that depending on the cell type used in the experiments, different nanoparticles responses were obtained. The intracellular pathway of each cell type, cellular metabolism or growth pattern can determine SNP toxicity. ${ }^{118,135}$ Although SNP physicochemical properties have an impact on biocompatibility and, consequently on their potential toxicity, nanoparticle concentration plays a singular role. Regardless the shape, size and surface functionalization of nanoparticles, for any type of cell there is a maximum concentration allowed before toxic effects occur. ${ }^{132}$

\section{Outlook}

During the last decades, fluorescent-based SNPs have earned an active role as bioimaging agents. These systems present interesting properties for these purposes and biocompatibility features. Hence, SNPs have been explored as promising platforms to accommodate photoluminescent organic dyes, metal complexes and other inorganic nanoparticles. In this context, surface functionalization methods earned a special attention and have been reviewed here. There is a wide range of molecules used in surface modification methods, that for example can start with a silane modification to a more specific chemical process using enzymes, peptides or antibodies. It is clear that all these efforts of tuning the silica surfaces properties have relevance in order to achieve nanoparticle stability in biological systems, specific targeting and therefore
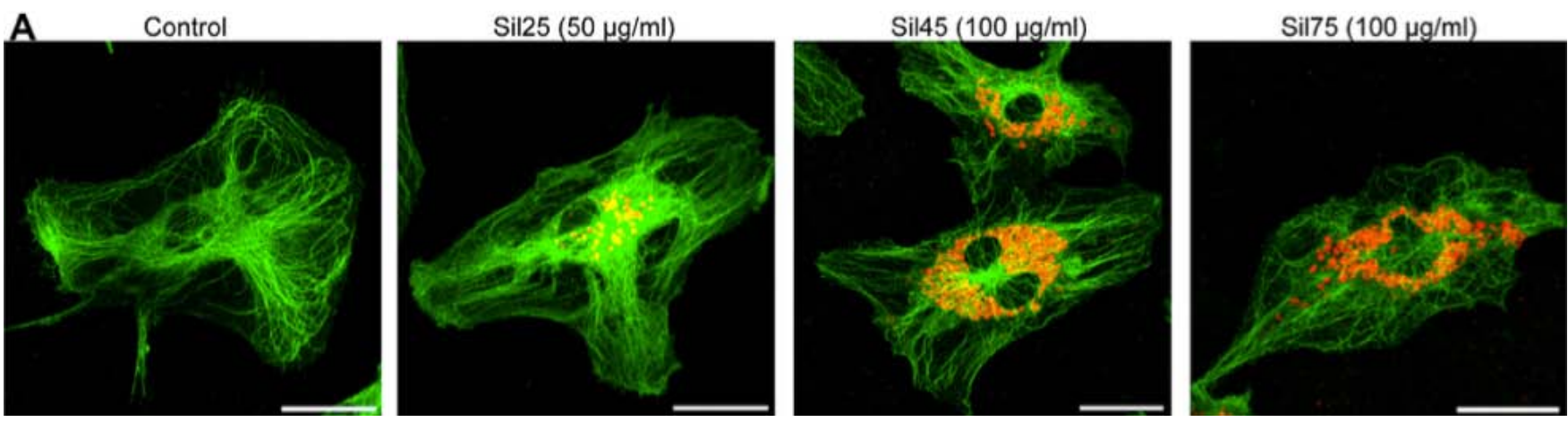

Fig. 8. Effect of silica particles on cell morphology. (a) Representative confocal images of control HUVEC cells (left) or HUVEC cells exposed for $24 \mathrm{~h}$ to Sil $25(25 \mathrm{~nm})$, Sil $45(45 \mathrm{~nm})$ or Sil $75(75 \mathrm{~nm})$ at noncytotoxic concentrations, being $50 \mu \mathrm{g} \mathrm{mL}-1,100 \mu \mathrm{g} \mathrm{mL}-1 \mathrm{and}$ $100 \mu \mathrm{g} \mathrm{mL}-1$, respectively. The images shown are merged images of both the SNP (red) and the a-tubulin cytoskeleton (green). Reprinted with permission from Ref. 122. Copyright (c) 2013 Acta Materialia Inc. with permission from Elsevier. 
improve biological responses. However, there is still a need in understanding the SNP-cells interactions and underlying mechanisms in order to develop safe and reliable clinical protocols that make widespread use of these systems. Here, fluorescent-based SNPs have brought some enlightenment, helping to understand and correlate SNP physicochemical properties and its biocompatibility.

\section{Acknowledgments}

Maria C. Gomes thanks FCT for her Ph.D grant (SFRH/BD/ 88334/2012. Thanks are due to Aveiro University and to $\mathrm{FCT} / \mathrm{MEC}$ for the financial support to QOPNA (FCT UID/QUI/00062/2013), CICECO-Aveiro Institute of Materials (FCT UID/ CTM/50011/2013), CESAM (FCT UID/MAR/ LA0017/2013) and CQE (FCT UID/QUI/0100/ 2013) research units, through national funds and where applicable cofinanced by the FEDER, within the PT2020 Partnership Agreement.

\section{References}

1. M. Montalti, L. Prodi, E. Rampazzo, N. Zaccheroni, "Dye-doped silica nanoparticles as luminescent organized systems for nanomedicine," Chem. Soc. Rev. 43, 4243-4268 (2014).

2. G. Wang, X. Su, "The synthesis and bio-applications of magnetic and fluorescent bifunctional composite nanoparticles," The Analyst 136, 17831798 (2011).

3. S. W. Bae, W. Tan, J.-I. Hong, "Fluorescent dye-doped silica nanoparticles: New tools for bioapplications," Chem. Commun. 48, 2270-2282 (2012).

4. Z. Q. Chu, S. L. Zhang, C. Yin, G. Lin, Q. Li, "Designing nanoparticle carriers for enhanced drug efficacy in photodynamic therapy," Biomater. Sci. 2, 827-832 (2014).

5. S. Walia, A. Acharya, "Silica micro/nanospheres for theranostics: From bimodal MRI and fluorescent imaging probes to cancer therapy," Beilstein J. Nanotechnol. 6, 546-558 (2015).

6. M. Z. Iqbal, X. Ma, T. Chen, L. E. Zhang, W. Ren, L. Xiang, A. Wu, "Silica-coated super-paramagnetic iron oxide nanoparticles (SPIONPs): A new type contrast agent of T1 magnetic resonance imaging (MRI)," J. Mater. Chem. B 3, 5172-5181 (2015).

7. C. Caltagirone, A. Bettoschi, A. Garau, R. Montis, "Silica-based nanoparticles: A versatile tool for the development of efficient imaging agents," Chem. Soc. Rev. 44, 4645-4671 (2015).

8. C. M. B. Carvalho, E. Alves, L. Costa, J. P. C. Tomé, M. A. F. Faustino, M. G. P. M. S. Neves, A. C. Tomé, J. A. S. Cavaleiro, A. Almeida, Â. Cunha, Z. Lin, J. Rocha, "Functional cationic nanomagnet-porphyrin hybrids for the photoinactivation of microorganisms," ACS Nano 4, 7133-7140 (2010).

9. E. Alves, J. M. M. Rodrigues, M. A. F. Faustino, M. G. P. M. S. Neves, J. A. S. Cavaleiro, Z. Lin, Â. Cunha, M. H. Nadais, J. P. C. Tomé, A. Almeida, A new insight on nanomagnet-porphyrin hybrids for photodynamic inactivation of microorganisms,", Dyes Pigments 110, 80-88 (2014).

10. D. Douroumis, I. Onyesom, M. Maniruzzaman, J. Mitchell, "Mesoporous silica nanoparticles in nanotechnology," Crit. Rev. Biotechnol. 33, 229-245 (2013).

11. L. Tang, J. Cheng, "Nonporous silica nanoparticles for nanomedicine application," Nano Today 8, 290-312 (2013).

12. Slowing, II, J. L. Vivero-Escoto, C. W. Wu, V. S. Lin, "Mesoporous silica nanoparticles as controlled release drug delivery and gene transfection carriers," $A d v$. Drug Delivery Rev. 60, 1278-1288 (2008).

13. M. Vallet-Regi, F. Balas, D. Arcos, "Mesoporous materials for drug delivery," Angew. Chem. Int. Ed. 46, 7548-7558 (2007).

14. W. Wei, M. Wei, S. Liu, "Silica nanoparticles as a carrier for signal amplification," Rev. Anal. Chem. 31, 163-176 (2012).

15. X. Wu, M. Wu, J. X. Zhao, "Recent development of silica nanoparticles as delivery vectors for cancer imaging and therapy," Nanomed. Nanotechnol. Biol. Med. 10, 297-312 (2014).

16. A. Bitar, N. M. Ahmad, H. Fessi, A. Elaissari, "Silicabased nanoparticles for biomedical applications," Drug Discovery Today 17, 1147-1154 (2012).

17. B. Sahoo, K. S. Devi, S. Dutta, T. K. Maiti, P. Pramanik, D. Dhara, "Biocompatible mesoporous silica-coated superparamagnetic manganese ferrite nanoparticles for targeted drug delivery and MR imaging applications," J. Colloid Interface Sci. 431, 31-41 (2014).

18. Y. Chen, K. Ai, J. Liu, G. Sun, Q. Yin, L. Lu, "Multifunctional envelope-type mesoporous silica nanoparticles for $\mathrm{pH}$-responsive drug delivery and magnetic resonance imaging," Biomaterials 60, 111-120 (2015).

19. J. Drbohlavova, J. Chomoucka, V. Adam, M. Ryvolova, T. Eckschlager, J. Hubalek R. Kizek, "Nanocarriers for anticancer drugs-new trends in nanomedicine," Curr. Drug Metab. 14, 547-564 (2013). 
20. D. Bechet, P. Couleaud, C. Frochot, M. L. Viriot, F. Guillemin, M. Barberi-Heyob, "Nanoparticles as vehicles for delivery of photodynamic therapy agents," Trends Biotechnol. 26, 612-621 (2008).

21. C. K. Lim, J. Heo, S. Shin, K. Jeong, Y. H. Seo, W. D. Jang, C. R. Park, S. Y. Park, S. Kim and I. C. Kwon, "Nanophotosensitizers toward advanced photodynamic therapy of Cancer," Cancer Lett. 334, 176-187 (2013).

22. I. Miletto, E. Bottinelli, G. Caputo, S. Coluccia, E. Gianotti, "Bright photoluminescent hybrid mesostructured silica nanoparticles," Phys. Chem. Chem. Phys. 14, 10015-10021 (2012).

23. A. Ebrahiminezhad, Y. Ghasemi, S. Rasoul-Amini, J. Barar, S. Davaran, "Preparation of novel magnetic fluorescent nanoparticles using amino acids," Colloids Surf. B 102, 534-539 (2013).

24. S.-W. Ha, C. E. Camalier, G. R. Beck, J.-K. Lee, "New method to prepare very stable and biocompatible fluorescent silica nanoparticles," Chem. Commun., doi: 10.1039/b902195g, 2881-2883.

25. S. Palantavida, N. V. Guz, I. Sokolov, "Functionalized ultrabright fluorescent mesoporous silica nanoparticles," Part. Part. Syst. Char. 30, 804-811 (2013).

26. J. Li, F. Liu, Q. Shao, Y. Min, M. Costa, E. K. Yeow, B. Xing, "Enzyme-responsive cell-penetrating peptide conjugated mesoporous silica quantum dot nanocarriers for controlled release of nucleustargeted drug molecules and real-time intracellular fluorescence imaging of tumor cells," Adv. Healthcare Mater. 3, 1230-1239 (2014).

27. M. Y. Chen, Z. Z. Chen, L. L. Wu, H. W. Tang, D. W. Pang, "Goat anti-rabbit IgG conjugated fluorescent dye-doped silica nanoparticles for human breast carcinoma cell recognition," The Analyst, 138, 7411-7416 (2013).

28. S. H. Wu, Y. Hung, C. Y. Mou, "Mesoporous silica nanoparticles as nanocarriers," Chem. Commun. 47, 9972-9985 (2011).

29. A. E. Nel, L. Madler, D. Velegol, T. Xia, E. M. V. Hoek, P. Somasundaran, F. Klaessig, V. Castranova M. Thompson, "Understanding biophysicochemical interactions at the nano-bio interface," Nat. Mater. 8, 543-557 (2009).

30. X.-R. Xia, N. A. Monteiro-Riviere J. E. Riviere, "An index for characterization of nanomaterials in biological systems," Nat. Nanotechnol. 5, 671-675 (2010).

31. G. Canton, R. Riccò, F. Marinello, S. Carmignato and F. Enrichi, "Modified Stöber synthesis of highly luminescent dye-doped silica nanoparticles," J. Nanopart. Res. 13, 4349-4356 (2011).

32. B. Korzeniowska, R. Nooney, D. Wencel, C. McDonagh, "Silica nanoparticles for cell imaging and intracellular sensing," Nanotechnology, 24, 442002 (2013).

33. J. Yan, M. C. Estévez, J. E. Smith, K. Wang, X. He, L. Wang, W. Tan, "Dye-doped nanoparticles for bioanalysis," Nano Today 2, 44-50 (2007).

34. F. Tang, L. Li and D. Chen, "Mesoporous silica nanoparticles: Synthesis, biocompatibility and drug delivery," Adv Mater, 24, 1504-1534 (2012).

35. Y. H. Jin, S. Lohstreter, D. T. Pierce, J. Parisien, M. Wu, C. Hall, J. X. J. Zhao, "Silica nanoparticles with continuously tunable sizes: Synthesis and size effects on cellular contrast Imaging," Chem. Mater. 20, 4411-4419 (2008).

36. L. Pan, Q. He, J. Liu, Y. Chen, M. Ma, L. Zhang and J. Shi, "Nuclear-targeted drug delivery of TAT peptide-conjugated monodisperse mesoporous silica nanoparticles," J. Am. Chem. Soc. 134, 57225725 (2012).

37. L. M. Rossi, L. Shi, F. H. Quina and Z. Rosenzweig, "Stober synthesis of monodispersed luminescent silica nanoparticles for bioanalytical assays," Langmuir, ACS J Surf. Colloids 21, 4277-4280 (2005).

38. W. Stober, A. Fink, E. Bohn, "Controlled growth of monodisperse silica spheres in micron size range," J. Colloid Interface Sci. 26, 62-\& (1968).

39. Y. Piao, A. Burns, J. Kim, U. Wiesner, T. Hyeon, "Designed fabrication of silica-based nanostructured particle systems for nanomedicine applications," Adv. Funct. Mater. 18, 3745-3758 (2008).

40. F. Figueira, J. A. S. Cavaleiro, J. P. C. Tomé, "Silica nanoparticles functionalized with porphyrins and analogs for biomedical studies," J. Porphyrins Phthalocyanines 15, 517-533 (2011).

41. K. D. Hartlen, A. P. T. Athanasopoulos, V. Kitaev, "Facile preparation of highly monodisperse small silica spheres ( 15 to $>200 \mathrm{~nm}$ ) suitable for colloidal templating and formation of ordered arrays," Langmuir, Acs J. Surf. Colloids 24, 1714-1720 (2008).

42. T. Yokoi, Y. Sakamoto, O. Terasaki, Y. Kubota, T. Okubo, T. Tatsumi, "Periodic arrangement of silica nanospheres assisted by amino acids," J. Am. Chem. Soc. 128, 13664-13665 (2006).

43. T. Yokoi, J. Wakabayashi, Y. Otsuka, W. Fan, M. Iwama, R. Watanabe, K. Aramaki, A. Shimojima, T. Tatsumi, T. Okubo, "Mechanism of formation of uniform-sized silica nanospheres catalyzed by basic amino acids," Chem. Mater. 21, 3719-3729 (2009).

44. J. Wang, Z. H. Shah, S. Zhang, R. Lu, "Silicabased nanocomposites via reverse microemulsions: Classifications, preparations, and applications," Nanoscale 6, 4418-4437 (2014). 
45. S. Santra, Cancer Nanotechnol, S. R. Grobmyer and B. M. Moudgil eds., Vol. 624, pp. 151-162, Humana Press (2010).

46. S. Santra, P. Zhang, K. M. Wang, R. Tapec, W. H. Tan, "Conjugation of biomolecules with luminophore-doped silica nanoparticles for photostable biomarkers," Anal. Chem. 73, 4988-4993 (2001).

47. R. P. Bagwe, C. Yang, L. R. Hilliard, W. Tan, "Optimization of dye-doped silica nanoparticles prepared using a reverse microemulsion method," Langmuir, ACS J. Surf. Colloids 20, 8336-8342 (2004).

48. S. Kim, T. Y. Ohulchanskyy, H. E. Pudavar, R. K. Pandey, P. N. Prasad, "Organically modified silica nanoparticles co-encapsulating photosensitizing drug and aggregation-enhanced two-photon absorbing fluorescent dye aggregates for two-photon photodynamic therapy," J. Am. Chem. Soc. 129, 2669-2675 (2007).

49. T. Y. Ohulchanskyy, I. Roy, L. N. Goswami, Y. Chen, E. J. Bergey, R. K. Pandey, A. R. Oseroff, P. N. Prasad, "Organically modified silica nanoparticles with covalently incorporated photosensitizer for photodynamic therapy of cancer," Nano Lett. 7, 2835-2842 (2007).

50. M. J. Ruedas-Rama, J. D. Walters, A. Orte, E. A. H. Hall, "Fluorescent nanoparticles for intracellular sensing: A review," Anal. Chim. Acta 751, 1-23 (2012).

51. A. Schulz, C. McDonagh, "Intracellular sensing and cell diagnostics using fluorescent silica nanoparticles," Soft Matter 8, 2579 (2012).

52. A. Singh, P. Sharma, S. Brown and B. Moudgil, "Luminescent and magnetic nanoparticulates as biomarkers," Kona Powder Part. J 28, 20-37 (2010).

53. S. Liang, K. Shephard, D. T. Pierce, J. X. Zhao, "Effects of a nanoscale silica matrix on the fluorescence quantum yield of encapsulated dye molecules," Nanoscale 5, 9365-9373 (2013).

54. A. Burns, H. Ow and U. Wiesner, "Fluorescent core-shell silica nanoparticles: Towards "Lab on a Particle" architectures for nanobiotechnology," Chem. Soc. Rev, 35, 1028-1042 (2006).

55. S. Yang, D. Lu, L. Tian, F. He, G. Chen, F. Shen, H. Xu, Y. Ma, "Stable water-dispersed organic nanoparticles: Preparation, optical properties, and cell imaging application," Nanoscale 3, 2261-2267 (2011).

56. H. Dong, Y. Liu, Z. Ye, W. Zhang, G. Wang, Z. Liu, J. Yuan, "Luminescent nanoparticles of silica-encapsulated cadmium-Tellurium (CdTe) quantum dots with a core - shell structure:
Preparation and Characterization," Helv. Chim. Acta 92, 2249-2256 (2009).

57. J. Xu, J. Liang, J. Li, W. Yang, "Multicolor dyedoped silica nanoparticles independent of FRET," Langmuir Acs J. Surf. Colloids 26, 15722-15725 (2010).

58. W. Wang, P. D. Nallathamby, C. M. Foster, J. L. Morrell-Falvey, N. P. Mortensen, M. J. Doktycz, B. Gu, S. T. Retterer, "Volume labeling with Alexa fluor dyes and surface functionalization of highly sensitive fluorescent silica ( $\mathrm{SiO} 2$ ) nanoparticles," Nanoscale 5, 10369-10375 (2013).

59. M. Al-Rawi, S. Diabate, C. Weiss, "Uptake and intracellular localization of submicron and nanosized $\mathrm{SiO}(2)$ particles in HeLa cells," Arch. Toxicol. 85, 813-826 (2011).

60. Y. Ma, Y. Li, S. Ma, X. Zhong, "Highly bright water-soluble silica coated quantum dots with excellent stability," J. Mater. Chem. B 2, 5043 (2014).

61. J. Cao, H. Niu, D. Han, S. Yang, Q. Liu, T. Wang, J. Yang, "Biocompatible $\mathrm{ZnS}: \mathrm{Mn}(2+)$ quantum dots/SiO2 nanocomposites as fluorescent probe for imaging HeLa cell," J. Mater. Sci. - Mater. Med. 26, 236 (2015).

62. M. Tan, G. Wang, X. Hai, Z. Ye, J. Yuan, "Development of functionalized fluorescent europium nanoparticles for biolabeling and time-resolved fluorometric applications," J. Mater. Chem. 14, 2896 (2004).

63. J. Wu, G. Wang, D. Jin, J. Yuan, Y. Guan, J. Piper, "Luminescent europium nanoparticles with a wide excitation range from UV to visible light for biolabeling and time-gated luminescence bioimaging," Chem. Commun., doi: 10.1039/ b715054g, 365 .

64. X. Guo, J.-L. Canet, D. Boyer, A. Gautier, R. Mahiou, "Sol-gel emulsion synthesis of biphotonic core-shell nanoparticles based on lanthanide doped organic-inorganic hybrid materials," J. Mater. Chem. 22, 6117 (2012).

65. O. D. Bochkova, A. R. Mustafina, A. R. Mukhametshina, V. A. Burilov, V. V. Skripacheva, L. Y. Zakharova, S. V. Fedorenko, A. I. Konovalov, S. E. Soloveva, I. S. Antipin, "The interfacial interactions of Tb-doped silica nanoparticles with surfactants and phospholipids revealed through the fluorescent response," Colloids Surf. B 92, 327-333 (2012).

66. H. Jiang, G. Wang, W. Zhang, X. Liu, Z. Ye, D. Jin, J. Yuan, Z. Liu, "Preparation and time-resolved luminescence bioassay application of multicolor luminescent lanthanide nanoparticles," J. Fluoresc. 20, 321-328 (2010). 
67. P. C. R. Soares-Santos, H. I. S. Nogueira, J. Rocha, V. Félix, M. G. B. Drew, R. A. Sá Ferreira, L. S. D. Carlos, T. Trindade, "Lanthanide complexes of 2-hydroxynicotinic acid: Synthesis, luminescence properties and the crystal structures of $[\mathrm{Ln}(\mathrm{HnicO}) 2(\mu$-HnicO $)(\mathrm{H} 2 \mathrm{O})] \cdot \mathrm{nH} 2 \mathrm{O}(\mathrm{Ln}=\mathrm{Tb}$, Eu)," Polyhedron 22, 3529-3539 (2003).

68. P. C. R. Soares-Santos, H. I. S. Nogueira, V. Felix, M. G. B. Drew, R. A. S. Ferreira, L. D. Carlos, T. Trindade, "Novel lanthanide luminescent materials based on complexes of 3-hydroxypicolinic acid and silica nanoparticles," Chem. Mater. 15, 100-108 (2003).

69. P. C. R, Soares-Santos, H. I. S. Nogueira, A. Filipe, A. Paz, A. Rute, Sá Ferreira, L. D. Carlos, J. Klinowski, T. Trindade, "Lanthanide complexes of 2,6-dihydroxybenzoic acid: Synthesis, crystal structures and luminescent properties of $[\mathrm{nBu} 4 \mathrm{~N}] 2$ [Ln(2,6-dhb)5(H2O)2] ( $\mathrm{Ln}=\mathrm{Sm}$ and $\mathrm{Tb}), "$ Eur. J. Inorg. Chem. 2003, 3609-3617 (2003).

70. H. Uh, S. Petoud, "Novel antennae for the sensitization of near infrared luminescent lanthanide cations," Comptes Rendus Chimie 13, 668-680 (2010).

71. H. Tsukube, "Lanthanide complexes in molecular recognition and chirality sensing of biological substrates," Chem. Rev. 102, 2389-2403 (2002).

72. C. Pitois, A. Hult, M. Lindgren, "Lanthanide-cored fluorinated dendrimer complexes: synthesis and luminescence characterization," J. Lumin. 111, 265-283 (2005).

73. S. Faulkner, S. J. A. Pope, P. B. Pye, "Lanthanide complexes for luminescence imaging applications," Appl. Spectrosc. Rev. 40, 1-31 (2005).

74. K. Binnemans, "Lanthanide-based luminescent hybrid materials," Chem. Rev. 109, 4283-4374 (2009).

75. Z. Gilles, Z. Asfari, J.-M. Lehnd, "Lanthanide complexes of encapsulating ligands: Luminescent devices at the molecular level," Pure Appl. Chem. 67, 135-140 (1995).

76. R. C. Leif, L. M. Vallarino, M. C. Becker, "Review: Increasing the luminescence of lanthanide complexes," Cytometry A 69, 767-778 (2006).

77. L. Tian, Z. Dai, L. Zhang, R. Zhang, Z. Ye, J. Wu, D. Jin, J. Yuan, "Preparation and time-gated luminescence bioimaging applications of long wavelength-excited silica-encapsulated europium nanoparticles," Nanoscale 4, 3551-3557 (2012).

78. C. M. Granadeiro, R. A. S. Ferreira, P. C. R. Soares-Santos, L. D. Carlos, T. Trindade, H. I. S. Nogueira, "Lanthanopolyoxotungstates in silica nanoparticles: Multi-wavelength photoluminescent core/shell materials," J. Mater. Chem. 20, 3313 (2010).
79. L. Zhang, L. Tian, Z. Ye, B. Song, J. Yuan, "Preparation of visible-light-excited europium biolabels for time-resolved luminescence cell imaging application," Talanta 108, 143-149 (2013).

80. Y. Wu, M. Shi, L. Zhao, W. Feng, F. Li, C. Huang, "Visible-light-excited and europium-emissive nanoparticles for highly-luminescent bioimaging in vivo," Biomaterials 35, 5830-5839 (2014).

81. J. H. Kim, H. H. Chung, M. S. Jeong, M. R. Song, K. W. Kang, J. S. Kim, "One-step detection of circulating tumor cells in ovarian cancer using enhanced fluorescent silica nanoparticles," Int. J. Nanomed. 8, 2247-2257 (2013).

82. Y. Qu, L. Feng, C. Tong, B. Liu, C. Lü, "Poly(pphenylenevinylene) functionalized fluorescent mesoporous silica nanoparticles for drug release and cell imaging, "Microporous Mesoporous Mater. 182, 155-164 (2013).

83. C. Miao, D. Li, Y. Zhang, J. Yu, R. Xu, "AIE luminogen functionalized mesoporous silica nanoparticles as efficient fluorescent sensor for explosives detection in water," Microporous Mesoporous Mater. 196, 46-50 (2014).

84. J. Liu, L. Zang, Y. Wang, G. Liu, "Preparation of acridine orange-doped silica nanoparticles for pH measurement," J. Lumin. 147, 155-158 (2014).

85. H. Tan, Q. Li, C. Ma, Y. Song, F. Xu, S. Chen, L. Wang, "Lanthanide based dual-emission fluorescent probe for detection of mercury (II) in milk," Biosens. Bioelectron. 63, 566-571 (2015).

86. S. Kralj, M. Rojnik, R. Romih, M. Jagodič, J. Kos, D. Makovec, "Effect of surface charge on the cellular uptake of fluorescent magnetic nanoparticles," J. Nanopart. Res. 14, 1151-1165 (2012).

87. E. Besic Gyenge, X. Darphin, A. Wirth, U. Pieles, H. Walt, M. Bredell and C. Maake, "Uptake and fate of surface modified silica nanoparticles in head and neck squamous cell carcinoma," J. Nanobiotechnol. 9, 32 (2011).

88. A. Liberman, N. Mendez, W. C. Trogler, A. C. Kummel, "Synthesis and surface functionalization of silica nanoparticles for nanomedicine," Surf. Sci. Rep. 69, 132-158 (2014).

89. X. He, H. Nie, K. Wang, W. Tan, X. Wu, P. Zhang, "In vivo study of biodistribution and urinary excretion of surface-modified silica nanoparticles," Anal. Chem. 80, 95979-603 (2008).

90. C. Morelli, P. Maris, D. Sisci, E. Perrotta, E. Brunelli, I. Perrotta, M. L. Panno, A. Tagarelli, C. Versace, M. F. Casula, F. Testa, S. Ando, J. B. Nagy, L. Pasqua, "PEG-templated mesoporous silica nanoparticles exclusively target cancer cells," Nanoscale 3, 3198-3207 (2011).

91. M. Li, J. W. Y. Lam, F. Mahtab, S. Chen, W. Zhang, Y. Hong, J. Xiong, Q. Zheng and B. Z. 
Tang, "Biotin-decorated fluorescent silica nanoparticles with aggregation-induced emission characteristics: Fabrication, cytotoxicity and biological applications," J. Mater. Chem. B 1, 676 (2013).

92. L. Cai, Z. Z. Chen, M. Y. Chen, H. W. Tang and D. W. Pang, "MUC-1 aptamer-conjugated dyedoped silica nanoparticles for MCF-7 cells detection," Biomaterials 34, 371-381 (2013).

93. K. Osseo-Asare, F. J. Arriagada, "Growth kinetics of nanosize silica in a nonionic water-in-oil microemulsion: A reverse micellar pseudophase reaction model," J. Colloid Interface Sci. 218, 68-76 (1999).

94. C. Haensch, S. Hoeppener, U. S. Schubert, "Chemical modification of self-assembled silane based monolayers by surface reactions," Chem. Soc. Rev. 39, 2323-2334 (2010).

95. N. Erathodiyil, J. Y. Ying, "Functionalization of inorganic nanoparticles for bioimaging applications," Acc. Chem. Res. 44, 925-935 (2011).

96. J. Zhao, Y. Liu, H. J. Park, J. M. Boggs, A. Basu, "Carbohydrate-coated fluorescent silica nanoparticles as probes for the galactose/3-sulfogalactose carbohydrate-carbohydrate interaction using model systems and cellular binding studies," Bioconjugate Chem. 23, 1166-1173 (2012).

97. M. Helle, E. Rampazzo, M. Monchanin, F. Marchal, F. Guillemin, S. Bonacchi, F. Salis, L. Prodi, L. Bezdetnaya, "Surface chemistry architecture of silica nanoparticles determine the efficiency of in vivo fluorescence lymph node mapping", $A C S$ Nano 7, 8645-8657 (2013).

98. H. L. Kim, S. B. Lee, H. J. Jeong, D. W. Kim, "Enhanced tumor targetability of PEGylated mesoporous silica nanoparticles on in vivo optical imaging according to their size," RSC Adv. 4, 31318 (2014).

99. H. Lee, D. Sung, J. Kim, B. T. Kim, T. Wang, S. S. An, S. W. Seo, D. K. Yi, "Silica nanoparticle-based dual imaging colloidal hybrids: Cancer cell imaging and biodistribution", Int. J. Nanomed. 10 Spec Iss, 215-225 (2015).

100. M. Xie, H. Shi, Z. Li, H. Shen, K. Ma, B. Li, S. Shen, Y. Jin, "A multifunctional mesoporous silica nanocomposite for targeted delivery, controlled release of doxorubicin and bioimaging," Colloids Surf. B 110, 138-147 (2013).

101. Y. Yang and J. Li, "Lipid, protein and poly (NIPAM) coated mesoporous silica nanoparticles for biomedical applications," Adv. Colloid Interface Sci. 207, 155-163 (2014).

102. J. Weingart, P. Vabbilisetty, X. L. Sun, "Membrane mimetic surface functionalization of nanoparticles: Methods and applications," $A d v$. Colloid Interface Sci. 197-198, 68-84 (2013).
103. M. Mahmoudi, I. Lynch, M. R. Ejtehadi, M. P. Monopoli, F. B. Bombelli, S. Laurent, "Proteinnanoparticle interactions: Opportunities and challenges," Chem. Rev. 111, 5610-5637 (2011).

104. A. Yang, W. Song, A. Wang, P. Zhu, J. Fei J. Li, "Lipid coated mesoporous silica nanoparticles as photosensitive drug carriers," Phys. Chem. Chem. Phys. 12, 4418-4422 (2010).

105. Y. Tang, Y. Zhao, X. Wang, T. Lin, "Layer-bylayer assembly of silica nanoparticles on $3 \mathrm{D}$ fibrous scaffolds: Enhancement of osteoblast cell adhesion, proliferation, and differentiation," J. Biomed. Mater. Res. Part A 102, 3803-3812 (2014).

106. Q.-L. Li, Y. Sun, Y.-L. Sun, J. Wen, Y. Zhou, Q.-M. Bing, L. D. Isaacs, Y. Jin, H. Gao, Y.-W. Yang, "Mesoporous silica nanoparticles coated by layer-by-layer self-assembly using cucurbit[7]uril for in vitro and in vivo anticancer drug release," Chem. Mater. doi: 10.1021/cm503304p.

107. S. O. Pereira, T. Trindade, A. Barros-Timmons, "Biotinylation of optically responsive gold/polyelectrolyte nanostructures," Gold Bull. 48, 3-11 (2014).

108. M. Corricelli, N. Depalo, E. Di Carlo, E. Fanizza, V. Laquintana, N. Denora, A. Agostiano, M. Striccoli, M. L. Curri, "Biotin-decorated silica coated $\mathrm{PbS}$ nanocrystals emitting in the second biological near infrared window for bioimaging," Nanoscale 6, 7924-7933 (2014).

109. C. M. Beddoes, C. P. Case, W. H. Briscoe, "Understanding nanoparticle cellular entry: A physicochemical perspective," Adv. Colloid Interface Sci. 218, 48-68 (2015).

110. O. Gamucci, A. Bertero, M. Gagliardi, G. Bardi, "Biomedical nanoparticles: Overview of their surface immune-compatibility," Coatings 4, 139-159 (2014).

111. P. M. Pereira, S. Silva, J. A. Cavaleiro, C. A. Ribeiro, J. P. Tome R. Fernandes, "Galactodendritic phthalocyanine targets carbohydratebinding proteins enhancing photodynamic therapy," PloS one 9, e95529 (2014).

112. P. M. Pereira, B. Korsak, B. Sarmento, R. J. Schneider, R. Fernandes, J. P. Tome, "Antibodies armed with photosensitizers: From chemical synthesis to photobiological applications," Org. Biomol. Chem. 13, 2518-2529 (2015).

113. A. Lesniak, F. Fenaroli, M. P. Monopoli, C. Åberg, K. A. Dawson, A. Salvati, "Effects of the presence or absence of a protein corona on silica nanoparticle uptake and impact on cells," ACS Nano 6, 5845-5857 (2012).

114. A. Verma, F. Stellacci, "Effect of surface properties on nanoparticle-cell interactions," Small 6, 12-21 (2010). 
115. F. Wahid, T. Khan, A. Shehzad, M. Ul-Islam, Y. Y. Kim, "Interaction of nanomaterials with cells and their medical applications," J. Nanosci. Nanotechnol. 14, 744-754 (2014).

116. A. Albanese, P. S. Tang, W. C. Chan, "The effect of nanoparticle size, shape, and surface chemistry on biological systems," Annu Rev Biomed. Eng. 14, 1-16 (2012).

117. S. Sandoval, N. Mendez, J. G. Alfaro, J. Yang, S. Aschemeyer, A. Liberman, W. C. Trogler, A. C. Kummel, "Quantification of endocytosis using a folate functionalized silica hollow nanoshell platform," J. Biomed. Opt. 20, 88003 (2015).

118. T. Asefa, Z. Tao, "Biocompatibility of mesoporous silica nanoparticles," Chem. Res. Toxicol. 25, 2265-2284 (2012).

119. C. O. Pritz, M. Bitsche, W. Salvenmoser, J. Dudas, A. Schrott-Fischer, R. Glueckert, "Endocytic trafficking of silica nanoparticles in a cell line derived from the organ of Corti," Nanomed. Nanotechnol. Biol. Med. 8, 239-252 (2013).

120. C. Argyo, V. Weiss, C. Bräuchle, T. Bein, "Multifunctional mesoporous silica nanoparticles as a universal platform for drug delivery," Chem. Mater. 26, 435-451 (2014).

121. S. Salatin, S. Maleki Dizaj, A. Yari Khosroushahi, "Effect of the surface modification, size, and shape on cellular uptake of nanoparticles," Cell Biol. Int. 39, 881-890 (2015).

122. M. C. Gomes, R. Fernandes, A. Cunha, J. P. Tome, T. Trindade, "Fluorescence biolabeling using methylated silica nanoparticles containing a lanthanide complex," J. Mater. Chem. B 1, 54295435 (2013).

123. I. Slowing, B. G. Trewyn, V. S. Y. Lin, "Effect of surface functionalization of MCM-41-type mesoporous silica nanoparticles on the endocytosis by human cancer cells," J. Am. Chem. Soc. 128, 14792-14793 (2006).

124. R. E. Yanes, D. Tarn, A. A. Hwang, D. P. Ferris, S. P. Sherman, C. R. Thomas, J. Lu, A. D. Pyle, J. I. Zink, F. Tamanoi, "Involvement of lysosomal exocytosis in the excretion of mesoporous silica nanoparticles and enhancement of the drug delivery effect by exocytosis inhibition," Small 9, 697704 (2013).

125. S. Shahabi, L. Treccani, R. Dringen, K. Rezwan, "Modulation of silica nanoparticle uptake into human osteoblast cells by variation of the ratio of amino and sulfonate surface groups: Effects of serum," ACS Appl. Mater. Interfaces 7, 1382113833 (2015).

126. J. Tu, T. Wang, W. Shi, G. Wu, X. Tian, Y. Wang, D. Ge, L. Ren, "Multifunctional ZnPc-loaded mesoporous silica nanoparticles for enhancement of photodynamic therapy efficacy by endolysosomal escape," Biomaterials 33, 7903-7914 (2012).

127. C. Fruijtier-Polloth, "The toxicological mode of action and the safety of synthetic amorphous silicaa nanostructured material," Toxicology 294, 61-79 (2012).

128. D. Napierska, L. C. Thomassen, D. Lison, J. A. Martens, P. H. Hoet, "The nanosilica hazard: Another variable entity," Part Fibre Toxicol. 7, 39 (2010).

129. M. Guo, X. Xu, X. Yan, S. Wang, S. Gao, S. Zhu, "In vivo biodistribution and synergistic toxicity of silica nanoparticles and cadmium chloride in mice," J. Hazard. Mater. 260, 780-788 (2013).

130. N. Hao, L. Li, Q. Zhang, X. Huang, X. Meng, Y. Zhang, D. Chen, F. Tang, L. Li, "The shape effect of PEGylated mesoporous silica nanoparticles on cellular uptake pathway in Hela cells," Microporous Mesoporous Mater. 162, 14-23 (2012).

131. D. Tarn, C. E. Ashley, M. Xue, E. C. Carnes, J. I. Zink, C. J. Brinker, "Mesoporous silica nanoparticle nanocarriers: Biofunctionality and biocompatibility," Acc. Chem. Res. 46, 792-801 (2013).

132. S. J. Soenen, B. Manshian, S. H. Doak, S. C. De Smedt, K. Braeckmans, "Fluorescent non-porous silica nanoparticles for long-term cell monitoring: Cytotoxicity and particle functionality," Acta biomaterialia 9, 9183-9193 (2013).

133. I. I. Slowing, C.-W. Wu, J. L. Vivero-Escoto, V. S. Y. Lin, "Mesoporous silica nanoparticles for reducing hemolytic activity towards mammalian red blood cells," Small 5, 57-62 (2009).

134. Q. He, J. Shi, "Mesoporous silica nanoparticle based nano drug delivery systems: Synthesis, controlled drug release and delivery, pharmacokinetics and biocompatibility," J. Mater. Chem. 21, 5845 (2011).

135. Y. Chen, H. Chen, J. Shi, "In vivo bio-safety evaluations and diagnostic/therapeutic applications of chemically designed mesoporous silica nanoparticles," Adv. Mater. 25, 3144-3176 (2013). 